\title{
The role of animacy in the production of Greek relative clauses
}

Sofia Loui and Silvia P. Gennari

Department of Psychology, University of York, U.K.

https://doi.org/10.36505/ExLing-2008/02/0037/000096

\begin{abstract}
This paper examines the effects of animacy on relative clauses production in Greek. Previous studies in English suggest that animacy influences structure preferences in main and relative clauses: animate entities are typically made the subject of the verb and this tendency often results in passive structures. In the present experiment, Greek speakers were presented with pictures depicting actions with an animate and an inanimate participant or two animate participants and they were asked to write answers to questions about the inanimate or the animate patients of these actions. The results were then compared to the results obtained in English and Spanish. Results suggest that animacy does not play a critical role in determining Greek structures, as it does in English, indicating that languagespecific constraints play a role in production mechanisms to a greater extent than conceptual factors such as animacy.
\end{abstract}

Key words: production, animacy, relative clauses, Greek

\section{Introduction}

Research suggests that language production is an incremental process (De Smedt, 1990, Ferreira, 1996): speakers start uttering words before the whole message is ready to be produced and they typically start their utterances with information that is easier to retrieve from memory. Words and concepts that are more difficult to retrieve tend to be produced later in the sentence. It has been proposed that animate entities (typically humans) are conceptually more accessible than inanimate ones, as they are more easily retrieved from memory (Bock and Warren, 1985). Thus, animate entities tend to appear in earlier sentence positions such as subjects, and this tendency sometimes results in a preference for passive structures (Bock, 1987). For example, to express the message that a truck hit a boy, English speakers are much more likely to say The boy was hit by the truck than The truck hit the boy. This is because the tendency to locate animate entities in subject position determines that the sentence will be continued in a passive structure, even though such structures are relatively rare in English. Thus, in English, animacy affects syntactic structure via syntactic function assignment and is linked to the production of passives when certain messages are conveyed.

ExLing 2008: Proceedings of 2nd Tutorial and Research Workshop on Experimental Linguistics, 25-27 August 2008, Athens, Greece 


\section{Previous work on relative clauses production}

Previous work also suggests that production of subordinate clauses such as relative clauses is also affected by animacy. Relative clauses provide information to identify a given participant for cases in which a noun phrase alone would not be sufficient. For example, in a situation in which there are two women, as in the present figure, the phrase the woman would not be sufficient to identify the woman being talked about, so a noun phrase modified by a relative clause such as the woman who is punching the bag would be required. For these structures, Gennari and Mac Donald (2008) argued that the head of the relative clauses is fixed in the initial sentence position due to

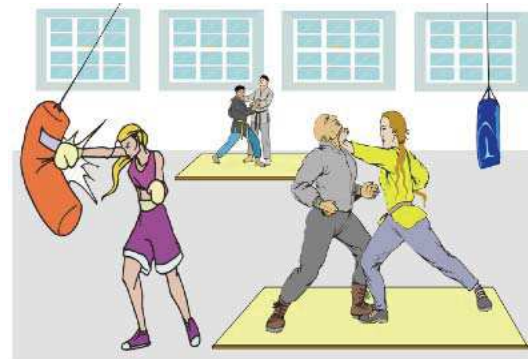
discourse considerations. But the word order within the relative clause may vary depending on the function of the head nouns with respect to the relative clause verb, as in The woman who is punching the bag (woman= subject) vs. the man that the woman is punching (man= object). To evaluate the role of animacy in relative clause production, Gennari, Mircovic and MacDonald (2005) presented English participants with pictures showing actions with an inanimate theme (a woman punching a bag) or an animate patient (a woman punching a man), as in the figure above, and they were asked questions relevant to the theme or the patient of the action (What is orange? Or Who is bold?). Results showed that when the question was about the animate patient, $96 \%$ of the responses were passive structures (e.g., The man who is being punched by the woman) but when the question was about the inanimate theme, only $48 \%$ were passives. Thus, for inanimate head nouns, many actives structures were produced (e.g., The bag that the woman is punching). These results indicate that in English, the animacy of the entity being talked about influences the type of structure (active or passive) that is eventually produced in relative clauses: animate entities are more likely to be produced as subjects of the relative clause verb and thus result in a passive structure.

\section{Differences in production preferences across languages}

One interesting question about these production preferences is whether languages with more flexible word order would also show preference for passive structures. In English, passives are necessary because subjects typically precede the verb, so when a noun has been uttered in initial position (due to its being more accessible), the only possible structural continuation is a passive structure, as in the boy was hit by the truck (the boy, 
the truck hit is not acceptable in English). Indeed, it has been shown that in languages like Spanish with more flexible word order than English, the tendency to locate animate entities in subject position is modulated by language-specific constraints, e.g., speaker may use dislocated active structures such as the boy, the truck hit (OSV order instead of the SVO canonical order) (Prat-Sala and Branigan, 2000). In these structures the word order changes, without any change in the syntactic function of the entities. Nevertheless, Spanish, like English, shows a preference for passive structures in relative clauses when talking about animate entities, although this preference is smaller than in English (only 56\% of animate responses were passives) (Gennari, Mircovic and MacDonald, 2005). Spanish also allows the use of impersonal constructions like the man to whom (they) are punching in relative clauses, making the continuation into a passive structure less likely. These findings suggest that conceptual accessibility constraints like those coming from animacy may manifest differently in different languages, depending on the grammatical possibilities of each language: when alternative structures are available, as in Spanish, the preference for passive is reduced compared to English.

The work presented here aims to explore the effects of animacy in the production of relative clauses in Greek, a language that shows flexibility in word order, such that any arrangement of subject, verb and object is grammatically licenced and independent of syntactic function. This study will indicate what structural possibilities are available in Greek and will help determine how language-specific rules interact with conceptual aspects of production processes such as those coming from animacy.

\section{Greek production in relative clauses}

30 Greek native speakers aged 18-35 years participated in the present experiment conducted via the web. They were presented with 20 pictures where an animate and an inanimate or two animate entities take part in an action. There were two conditions. For each picture, each participant answered one question either about the animate patient (animate condition) or about the inanimate theme (inanimate condition) (see example above). All participants were asked equal number of questions from both conditions and they produced their answers in written form. Participants were advised to focus on the action of the sentence and not on the theme's or patient's location in the picture, their clothes or colours. 40 filler items were also included in the experiment that encouraged participants to produce different types of clauses, other than relative ones. Before the experimental trials, participants were provided with examples. The responses were coded by active versus passive relative clause structures. The pictures and procedure of this study were the same as in the previous English and Spanish studies. 
The results indicate that there is an overall preference in Greek speakers to use more active than passive structures in both conditions. They used $87 \%$ and $97 \%$ active structures for the animate and the inanimate condition respectively. Hence, they were more likely to produce active structures like The man/the bag that the woman is punching then passive structures like The man/the bag that is being punched by the woman. However, they were more likely to produce passive structures when answering the questions about animate patients (animate condition) than about inanimate themes (inanimate condition). They showed a $13 \%$ significant preference in producing more passive structures in the animate condition compared to $3 \%$ of passive structures production in the inanimate condition. This preference is much smaller than in Spanish (56\%) and even smaller than in English (96\%).

These results suggest that language-specific constraints play a role in language production. The effect of animacy on sentence structure, which is associated with conceptual accessibility and ease of retrieval, is minimal in Greek, whereas it is critical in English structural preferences. It is possible that in Greek, passive structures are not really accessible to speakers so that active structures must be produced. This makes language-specific constraints more critical than conceptual factors in determining sentence structure. However, if animacy matters, this may come at a greater cost in planning the utterance and thus may require more planning time. This possibility is currently being investigated.

\section{References}

Bock, J.K. 1987. Coordinating words and syntax in speech plans. In A. Ellis (ed) Progress in the pathology of language. London: Erlbaum.

Bock, J.K. and Warren, R.K. 1985. Conceptual accessibility and syntactic structure in sentence formulation. Cognition, 21, 47-67.

De Smedt, K.J. 1990. IPF: An incremental parallel formulator. In R. Dale, C. Mellish and M. Zock (Eds.), Current research in natural language generation, Cognitive Science Series (pp. 167-192). San Diego:Academic Press.

Ferreira, V.S. 1996. Is it better to give than to donate? Syntactic flexibility in language production. Journal of Memory and Language, 35, 724-755.

Gennari, S.P., McDonald, M. C. 2008. Linking production and comprehension processes: The case of Relative clauses. submitted.

Gennari, S.P., Mirkovic, J. And MacDonald, M. C. 2005. The role of animacy in relative clause production. Paper presented at the 17th Annual Cuny Conference on Human Sentence Processing.

McDonald, J.L., Bock, J.K. and Kelly, M.H. 1993. Word and world order: Semantics, phonological, and metrical determinants of serial position. Cognitive Psychology, 25, 188-230.

Prat-Sala, M. and Branigan, H.P. 2000. Discourse constraints on syntactic processing in language production: A cross-linguistic study in English and Spanish. Journal of Memory and Language, 42(2), 168-182. 